\title{
Hepatitis B virus infections among health professional students in Mwanza city,Tanzania in 2016
}

Mariam M. Mirambo ${ }^{1}$, Emmanuel Mkumbo ${ }^{1}$, Hadija Selega ${ }^{1}$, Betrand Msemwa², Martha F. Mushi ${ }^{1}$ Vitus Silago ${ }^{1}$, Jeremiah Seni ${ }^{1}$, Stephen E. Mshana ${ }^{1 *}$ and Christa Kasang ${ }^{3}$

\begin{abstract}
Background: The World Health Organisation (WHO) recommends the vaccination against Hepatitis B virus in all infants and children up to the age of 18 years. In addition, adults in high-risk groups should also be vaccinated. This study investigated the prevalence and factors associated with Hepatitis B Virus (HBV) infections among health professional students in the city of Mwanza, Tanzania in order to provide data that can assist in devising prevention and control strategies in this special group.

Methods: A cross-sectional study involving health professional students of the Catholic University of health and Allied Sciences was conducted between April and July 2016. Hepatitis B surface antigen was detected using rapid antigen test while the anti-hepatitis B surface antibodies(anti-HBs) were quantified using Enzygnost Anti-HBs II assay and anti-HBV core antibodies tested using enzyme immunoassay.

Results: A total of 1211 health professional students with median age of 22 interquartile range (IQR):21-24 years were enrolled. The slighlty majority (57.5\%) of these students were males and $475(39.2 \%)$ were in clinical practices. Out of 1211 students, 37 (3.1\%) were Hepatitis B surface antigen positive. Of 1174 students tested for anti-HBs, 258 (22\%) had titres > $10 \mathrm{IU} / \mathrm{L}$ indicating HBV immunity. The median anti-HBs titres was $47.7 \mathrm{IU} / \mathrm{L}(\mathrm{IQR}: 16-3-113)$. A total of 230(89.2\%) students among those who were positive for anti-HBs were also positive for HBV core antibodies indicating HBV natural infections. Male sex (adjusted odd ratio(AOR):1.77, $p<0.000$ ), being married (AOR:1.82, $p=0.002$ ) and being in clinical practices (AOR:1.39, $p=0.028$ ) independenlty predicted anti-HBs positivity.

Conclusion: A significant proportion of health professional students was naturally immune to Hepatitis B virus. There is a need to measure anti-HBs in order to reduce the cost of unnecessary vaccination especially in the countries with high endemicity of HBV.
\end{abstract}

Keywords: Anti-HBs, HBsAg, Anti HBV-core, Students, Tanzania

\footnotetext{
* Correspondence: stephen72mshana@gmail.com

${ }^{1}$ Department of Microbiology and Immunology, Weill Bugando School of Medicine, Catholic University of Health and Allied sciences, P.O.Box 1464, Mwanza, Tanzania

Full list of author information is available at the end of the article
}

(c) The Author(s). 2020 Open Access This article is licensed under a Creative Commons Attribution 4.0 International License, which permits use, sharing, adaptation, distribution and reproduction in any medium or format, as long as you give appropriate credit to the original author(s) and the source, provide a link to the Creative Commons licence, and indicate if changes were made. The images or other third party material in this article are included in the article's Creative Commons licence, unless indicated otherwise in a credit line to the material. If material is not included in the article's Creative Commons licence and your intended use is not permitted by statutory regulation or exceeds the permitted use, you will need to obtain permission directly from the copyright holder. To view a copy of this licence, visit http://creativecommons.org/licenses/by/4.0/ The Creative Commons Public Domain Dedication waiver (http://creativecommons.org/publicdomain/zero/1.0/) applies to the data made available in this article, unless otherwise stated in a credit line to the data. 


\section{Background}

Approximately one third of the global population is infected by Hepatitis B virus(HBV) [1] with about 350400 million people being chronically infected [2]. High endemicity of HBV is observed in the sub-Saharan Africa and East Asia whereby $5-10 \%$ of the adult population is chronically infected. Health professional students are among high risk groups of being infected with the HBV especially during early stage of their clinical practices [3]. Among health care workers the prevalence of chronic infection of $7.4 \%$ has been oberved in Tanzania [4] while in Cameroon the prevalence of chronic HBV infection was found to be $11 \%$ [5], indicating high endemicity in these countries.

A previous study done at Bugando Medical Centre among health care workers documented the prevalence of HBV natural antibodies of 36.5\%, indicating high transmission of HBV infections [4]. However, there is limited information on the magnitude of anti-HBs among health professional students who are also considered as high-risk group that requires vaccination. In addition, the current vaccination practices among children below 5 year of age and among health care workes in Tanzania and in many low-icome countries do not consider the presence of natural antibodies leading to the possibility of unnecessary vaccination in a significant proportion of individuals [6]. Most of studies from lowincome countries have estimated the magnitude of chronic HBV infections, with few studies documenting the magnitude of the immunity to $\operatorname{HBV}[4,7,8]$. It should be noted that, the use of Hepatitis B surface antigen $(\mathrm{HbsAg})$ does not indicate the true magnitude of HBV infections because the HbsAg indicates only those with chronic/acute infections and not those who have recovered from natural infections. Therefore, in order to combat HBV, the pathogen which has been mentioned in sustainable developmental goals (SDG) 'Health Goal', this study was done to estimate the prevalence of HBV infections among health professional students in order to produce data that can be used to formulate strategies to control HBV infections in this high risk population.

\section{Methods}

\section{Study design, pupulation and area}

This was a cross-sectional study which was conducted between April and July 2016 among undergraduate health professional students of the Catholic University of health and Allied Sciences. The Catholic University of Health and Allied sciences is the private University located in the city of Mwanza, Tanzania. It has about 2600 students in various field of health sciences. The study included students from medical laboratory sciences, nursing, medical doctors, radiology and pharmacy programmes.
Sample size, sampling technique and inclusion criteria The sample size was estimated by Kish Leslie formula (1965) using the prevalence of $56.7 \%$ from previous study which was conducted at Bugando Medical Centre [9] among health care professionals. The minimum sample obtained was 377, however the study enrolled 1211 students. The study included all undergraduate students who consented to participate in the study with no history of HBV vaccination or known positivity of hepatitis B surface antigen. A recruitment centre was set at the University campus for 4 days and serial sampling was used to recruit students as they pass around the recruitment centre. The study did not exclude students on clinical practices because, the aim was establish the magnitude and factors associated with HBV infection. Clinical practices was treated as a factor to confirm what has been documented in previous studies.

\section{Data collection}

A pretested data collection tool was used to collect socio-demographic information and other related information from study participants. Data collected included age, sex, duration on clinical practices, marital status, histroy of unproteced sex etc.

\section{Hepatitis B surface antigen, anti-hepatitis B surface antibodies(anti-HBs) and anti-hepatitis B core(anti-HBc) assays}

About 5-ml of venous blood sample was collected in a plain vacutainer tube(BD, Nairobi, Kenya) under aseptic procedures. Samples were transported to the CUHAS microbiology laboratory whereby blood was centrifuged to obtain sera which was stored in cryovials at $-80^{\circ} \mathrm{C}$ until analysis. Hepatitis B surface antigen was detected using a qualitative, lateral flow immunochromotography assay test (Accu-Tell Rapid HBsAg Serum/Whole Blood Test, Beijing,101,300,China) following manufacturer instructions. The test has been found to have sensitivity and specificity of $>99.0$ and $97.0 \%$, respectively. The anti-HBs were detected using Sandwich ELISA test kit (SIEMENS Enzygnost, Germany) following manufacturer's instructions, the assay has sensitivity and specificity of more than $95 \%$ while anti-HBc antibodies were detected using enzyme immunoassay (Elite Medical Company, India) as per manufacturer instructions, this assay has sensitivity and specificity of more than $95 \%$.

\section{Data analysis}

Continuous variables were summarized as median with inter-quartile range while categorical variables were summarized as proportions. Univariable analysis was done followed by multivariable logistic regression analysis to determine the predictors of $\mathrm{HBsAg}$ positivity and the presence of anti-HBs. The titre of anti-HBs of $\geq 10$ 
IU/L was considered as the presence of natural immunity to HBV. The medians were compared using the Wilcoxon rank-sum Mann Whitney test. Factors with a $p$ value of $<0.2$ on univariable analysis were subjected into multivariable logistic regression analysis. All factors with $p$-values of $<0.05$ at $95 \%$ confidence interval were considered statistically significant. Age was not subjected on the multivariable analysis due to its collinearity with being in clinical practices.

\section{Results}

Sociodemographic characteristics of the study participants

A total of 1211 students were enrolled, representing $46 \%$ of the Catholic University of Health and Allied Sciences students' population in 2016. The median age was 22[IQR:21-25] years with the slightly majority $57.5 \%$ $(696 / 1211)$ of the students being male. Regarding marital status, the majority of the participants $86.1 \%$ (1043/ 1211) were single. Out of 1211 students, $475(39 \%)$ had started clinical practices(Table 1). None of these students had received $\mathrm{HepB}$ vaccination before.

Prevalence of hepatitis B surface antigen and anti-HBsAg Out of 1211 students tested for hepatits B surface antigen(HbsAg), 37(3.1, 95\%CI: 2.1-4.0) were HbsAg positive. All students (1174) who were $\mathrm{HBsAg}$ negative were tested for anti-HbsAg, of these, 258(22, 95\%CI: 19.624.4) had titres $>10 \mathrm{IU} / \mathrm{L}$, indicating immunity to $\mathrm{HBV}$. Low, moderate and high anti-HBs titers were observed in $69.4 \%(179 / 258), 25.2 \%(65 / 258)$ and $5.4 \%(14 / 258)$ students, respectively (Table 2 ). The median anti-HBs titres was $47.7 \mathrm{IU} / \mathrm{L}(\mathrm{IQR}: 16-3-113)$. Out of 258 tested positive for anti-HBs, 230(89.2\%) were positive for anti$\mathrm{HBc}$ indicating natural infections.
Table 2 Prevalence of Hebatitis B surface antigen and Anti$\mathrm{Hbs} A g$ antibodies among health professional students from CUHAS, April to July 2016, Mwanza, Tanzania

\begin{tabular}{lll}
\hline Variable & $\mathbf{n}$ & \% \\
\hline Hepatitis B surface antigen $(\boldsymbol{N}=\mathbf{1 2 1 1})$ & 37 & 3.1 \\
HbsAb Status $(\boldsymbol{N}=\mathbf{1 1 7 4})$ & & \\
$\quad$ Positive $[\geq 10 \mathrm{IU} / \mathrm{L}]$ & 258 & 22.0 \\
$\quad$ Negative $[<10 \mathrm{IU} / \mathrm{L}]$ & 916 & 78.0 \\
Anti-HBs titres $(\mathbf{2 5 8})$ & & \\
$\quad$ High $[>200 \mathrm{IU} / \mathrm{L}]$ & 14 & 5.4 \\
$\quad$ Moderate $[100-200 \mathrm{IU} / \mathrm{L}]$ & 65 & 25.2 \\
$\quad$ Low $[10-100 \mathrm{IU} / \mathrm{L}]$ & 179 & 69.4 \\
\hline
\end{tabular}

Factors associated with HBV infections among health professional students

The median age of partcipants with HBV immunity was significantly higher than those with no immunity (23 IQR;22-26 vs. 22 IQR; $21-24, P<0.001)$. Out of 502 females, $81(16.1 \%)$ were positive for anti-HBs compared to $177(26.3 \%)$ of 672 males, $p<0.001$. Being in clinical practices was found to be associated with the presence of anti-HBs $(27.2 \%$ vs. $18.7 \%, P=0.001)$. By multivariable logistic regression analysis; male sex (OR:1.77, 95\% CI:1.31-2.38), being married (OR:1.82, 95\% CI:1.252.64) and being in clinical practices (OR:1.39, 95\% CI: 1.03-1.86) were found to predict anti-HBs positivity (Table 3). None of the factors studied (sex, age, clinical practices, marital status and practice unprotected sex) were found to be associated with $\mathrm{HBsAg}$ positivity.

\section{Discussion}

The overall prevalence of HBsAg was $3.1 \%$ among CUHAS health professional students. The observed prevalence was significantly lower than what was reported in previous studies in Makerere Uganda (18\%)

Table 1 Sociodemographic and clinical characteristics of unvaccinated health professional students at Catholic University of Health and Allied Sciences, April to July 2016, Mwanza Tanzania

\begin{tabular}{|c|c|c|c|c|}
\hline \multirow[t]{2}{*}{ Participant Characteristics } & \multicolumn{2}{|c|}{1174 students tested anti-HBs } & \multicolumn{2}{|c|}{1211 students tested anti-HBs } \\
\hline & Number & Percent[\%]/Median [IQR] & Number & 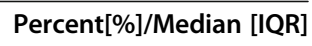 \\
\hline Age IQR [years] & 1174 & $22[21-24]$ years & 1211 & $22(21-25)$ years \\
\hline \multicolumn{5}{|l|}{ Sex } \\
\hline Male & 672 & 57.24 & 696 & 57.5 \\
\hline Female & 502 & 42.76 & 515 & 42.5 \\
\hline \multicolumn{5}{|l|}{ Marital Status } \\
\hline Single & 1014 & 86.37 & 1025 & 84.6 \\
\hline Married & 160 & 13.63 & 186 & 15.4 \\
\hline \multicolumn{5}{|l|}{ Clinical Practise } \\
\hline Yes & 458 & 39.01 & 475 & 39 \\
\hline No & 716 & 60.99 & 736 & 61 \\
\hline
\end{tabular}


Table 3 Factors associated with anti-HBsAg among 1174 unvaccinated health professional CUHAS students April to July 2016, Mwanza, Tanzania

\begin{tabular}{|c|c|c|c|}
\hline Variable & Anti-HBsAg & $\begin{array}{l}\text { Univariate } \\
\text { OR[95\%Cl] }\end{array}$ & $\begin{array}{l}\text { Mutivariable } \\
\text { OR[95\% Cl] }\end{array}$ \\
\hline Age (yrs) & $23 \mathrm{IQR}[22-26]$ & $1.05[1.03-1.07]$ & \\
\hline \multicolumn{4}{|l|}{ Sex } \\
\hline Female & 81 [16.14] & 1 & \\
\hline Male & 177 [26.34] & $1.85[1.38-2.49]$ & $1.77[1.31-2.38]$ \\
\hline \multicolumn{4}{|c|}{ Marital Status } \\
\hline Single & 205 [20.22] & 1 & \\
\hline Married & 53 [33.13] & $1.95[1.35-2.81]$ & $1.82[1.25-2.64]$ \\
\hline \multicolumn{4}{|c|}{ Clinical Practices } \\
\hline No & 134 [18.72] & 1 & \\
\hline Yes & 124 [27.07] & $1.61[1.22-2.13]$ & 1.39 [1.03-1.86] \\
\hline \multicolumn{4}{|c|}{ Unprotected Sex } \\
\hline No & $173[20.50]$ & 1 & \\
\hline Yes & 85 [25.76] & 1.34 [0.99-1.81] & $1.06[0.77-1.46]$ \\
\hline
\end{tabular}

and in Kenyatta National hospital(11\%) among medical students [10, 11]. The low prevalence of HBsAg could indicate high natural immunity in this population or high vaccine coverage, however this was not the case in this population because none of student had received HBV vaccination. In Tanzania, at the time of data collection the HBV immunization programme for children below 5 years of age was just 6 years old, therefore it was unlikely that these students were immunized before.

In this study, the overall prevalence of anti-HBs was found to be $22 \%$ with $89.2 \%$ of these students being positivite for anti-HBc indicating that, the majority of anti-HBs were due to natural infections. This was comparable with a previous study in South Africa [12] which reported prevalence of $18.8 \%$ among health care workers. However, when compared to the prevalence of immunity among the students who were in clinical practices the oberved prevalence of HBV immunty in the current study was significantly high indicating high transmission of HBV in this setting. The observation was further supported by the previous study in the same setting which observed the prevalence of natural immunity of $36.5 \%$ among health care workers. However, the observed immunity in the current study was comparable to $25.3 \%$ observed among febrile patients in two districts hospitals in Tanzania [13].

The difference between this study and that of South Africa could be explained by the fact that in South Africa the HBV vaccination among health care workers was introduced earlier than in Tanzania [5, 14]. South Africa and Tanzania has similar endemicity status as per World Health Organization (WHO), this further supports the similarity in the general prevalence of $\mathrm{HBV}$ natural immunity.

In comparison to the previous study in China which reported the prevalence of $13 \%$, the prevalence reported in this study is indeed high [15]. This could be due to the fact that in China HBV vaccination campaign has been there for many years [16].

None of the factors studied was found to predict HbsAg positivity, however male sex, being married and being in clinical practices were found to predict anti-HBs positivity in the present study. Previous studies [4, 17] showed the association between HBV infection and the duration of employment/clinical practices, emphasizing the need to vaccinate health professional students to prevent subsequent infections.

In this study male sex was significantly associated with HBV immunity. This could be explained by the fact that in Tanzania boys tend to be more involved in high risk behaviours than girls [18]. Further multi -centre studies to asess the association between HBV infections and gender among students are recommended so that tartegted health education can be given. Furthermore, being married was found to predict HBV natural infections in this study confriming what was oberved in previous studies $[19,20]$.

It should be noted that the 96 ELISA kit for for screening of the anti-HBs costs about 500 USD(i.e. about 6USD per test) compared to the cost of single dose HBV vaccine of about 12.3USD [19]. Therefore, screening for anti-HBs should be recommnded in the countries with HBV high endemicity in order to avoid unnecessary costly vaccination. A previous study in China concluded that HepB vaccination campaign with screening provided more greater value than a vaccination without screening vaccination [19]. Furthermore, there is a need to invest on point of care anti-HBs assays that can be used in developing countries to asses the level of antiHBs before vaccination.

In this study non significant association was observed between unprotected sexual intercourse and HBV infections. This could be contributed to the validity of the self-response regarding the issues of unprotected sexual intercourse. Self reports on the issue of sexual behaviours can be affected by both cognitive and situational factors in varying degrees [21]. As major limitation no attempt was made to validate the information given from these students due the design of this study.

\section{Conclusion}

A significant proportion of students undertaking health sciences courses were found to be naturally immune to HBV. The immunity was significanlty predicted by male sex, being in clinical practices and being married. This calls for the need to emphasize the screening for the 
presence of anti-HBs so that the vaccine can be given to those who are eligible to avoid waste vaccinations among those with natural immunity, this will ensure costeffective implementation of of $\mathrm{HBV}$ vaccination programme. If the implementation of universal screening for antiHBs is considered as difficult option, it is recommended that in the Higher learning institutions for health in developing countries, married-male students in their clinical practices should mandatory be screened for antiHBs before provision of HBV vaccination. This will significantly minimize the cost of $\mathrm{HBV}$ vaccination to the institutions and respective individual students.

\section{Abbreviations}

CUHAS: Catholic University of Health and Allied Sciences; Cl: Confidence interval; ELISA: Enzyme-linked immunosorbent assay; HBV: Hepatitis B Virus; HBs: Hebatitis B surface antitigen; HBc: Hebatitis B core antigen; IU: International Unit; IQR: Interquartile range; OR: Odd ratio

\section{Acknowledgements}

The authors would like to acknowledge the technical support provided by Dr. Peter Maskini and Dr. Hysinta Jaka, Mr. Seif Abdu and all staff of the Bugando medical centre laboratory.

\section{Authors' contributions}

MMM, CK and SEM participated in the design of the study. SEM, MMM, EM,HS, MFM, JS, VS and BM participated in the collection of specimens and data. EM, HS, MMM and SEM performed serological tests. MMM and SEM analysed and interpreted the data. MMM wrote the first draft of the manuscript. All authors read and approved the final version of the manuscript.

\section{Funding}

This research was supported by research grant from CUHAS to MMM and ELISA KITS from SIEMEN, GERMANY to CK.

\section{Availability of data and materials}

The data is available upon request and the request should be made to the Director of research and Innovation Catholic University of Health and allied Sciences.

\section{Ethics approval and consent to participate}

The study obtained the ethical clearance from the joint CUHAS-BMCresearch ethics and review committee (CREC) with ethical clearance number 303/2017. All participants were asked to sign informed consent prior enrollment.

\section{Consent for publication}

Not applicable.

\section{Competing interests}

None declared.

\section{Author details}

${ }^{1}$ Department of Microbiology and Immunology, Weill Bugando School of Medicine, Catholic University of Health and Allied sciences, P.O.Box 1464, Mwanza, Tanzania. ${ }^{2}$ Institute of Allied Health Sciences, Catholic University of Health and Allied sciences, P.O.Box 1464, Mwanza, Tanzania. ${ }^{3}$ Deutsche Lepra- und Tuberkulosehilfe e.V, Raiffeisenstr.3, 97080 Würzburg, Germany.

Received: 2 March 2020 Accepted: 12 August 2020

Published online: 18 August 2020

\section{References}

1. Hwang EW, Cheung R. Global epidemiology of hepatitis B virus (HBV) infection. N Am J Med Sci. 2011;4(1):7-13.

2. McMahon BJ. Epidemiology and natural history of hepatitis B. In: Seminars in liver disease; 2004. p. 3-8.
3. Wang $\mathrm{H}$, Fennie $\mathrm{K}, \mathrm{He} \mathrm{G}$, Burgess J, Williams AB. A training programme for prevention of occupational exposure to bloodborne pathogens: impact on knowledge, behaviour and incidence of needle stick injuries among student nurses in Changsha, People's Republic of China. J Adv Nurs. 2003:41(2):187-94.

4. Mueller A, Stoetter L, Kalluvya S, Stich A, Majinge C, Weissbrich B, Kasang C. Prevalence of hepatitis B virus infection among health care workers in a tertiary hospital in Tanzania. BMC Infect Dis. 2015;15(1):386.

5. Tatsilong HOP, Noubiap JJN, Nansseu JRN, Aminde LN, Bigna JJR, Ndze VN, Moyou RS. Hepatitis B infection awareness, vaccine perceptions and uptake, and serological profile of a group of health care workers in Yaoundé, Cameroon. BMC Public Health. 2016;16(1):706.

6. Organization WH. Hepatitis B vaccines: WHO position paper, July 2017recommendations. Vaccine. 2019;37(2):223-5.

7. Tandon B, Irshad M, Raju M, Mathur G, Rao M. Prevalence of HBsAg \& antiHBs in children \& strategy suggested for immunisation in India. Indian J Med Res. 1991;93:337-9.

8. Soběslavský O. Prevalence of markers of hepatitis $B$ virus infection in various countries: a WHO collaborative study. Bull World Health Organ. 1980;58(4):621.

9. Mueller A, Stoetter L, Kalluvya S, Stich A, Majinge C, Weissbrich B, Kasang C. Prevalence of hepatitis $B$ virus infection among health care workers in a tertiary hospital in Tanzania. BMC Infect Dis. 2015;15(1):1.

10. Pido B, Kagimu M. Prevalence of hepatitis B virus (HBV) infection among Makerere University medical students. Afr Health Sci. 2005;5(2):93-8.

11. Lule G, Okoth F, Ogutu E, Mwai S. HBV markers HBsAg, HBSAb, HBCAb in 160 medical students at Kenyatta National Hospital. East Afr Med J. 1989; 66(5):315-8.

12. Sondlane TH, Mawela L, Razwiedani LL, Selabe SG, Lebelo RL, Rakgole JN, Mphahlele MJ, Dochez C, De Schryver A, Burnett RJ. High prevalence of active and occult hepatitis B virus infections in healthcare workers from two provinces of South Africa. Vaccine. 2016;34(33):3835-9.

13. Meschi S, Schepisi MS, Nicastri E, Bevilacqua N, Castilletti C, Sciarrone MR, Paglia MG, Fumakule R, Mohamed J, Kitwa A. The prevalence of antibodies to human herpesvirus 8 and hepatitis B virus in patients in two hospitals in Tanzania. J Med Virol. 2010;82(9):1569-75.

14. Burnett RJ, Kramvis A, Dochez C, Meheus A. An update after 16 years of hepatitis B vaccination in South Africa. Vaccine. 2012;30:C45-51.

15. Liao $X-Y$, Zhou Z-Z, Wei F-B, Qin H-N, Ling Y, Li R-C, Li Y-P, Nong Y, Sun K-X, $\mathrm{Li} J$. Seroprevalence of hepatitis $B$ and immune response to hepatitis $B$ vaccination in Chinese college students mainly from the rural areas of western China and born before HBV vaccination integrated into expanded program of immunization. Human Vaccines Immunotherapeutics. 2014; 10(1):224-31.

16. Liang X, Bi S, Yang W, Wang L, Cui G, Cui F, Zhang Y, Liu J, Gong X, Chen Y. Reprint of: epidemiological serosurvey of hepatitis $B$ in China-declining HBV prevalence due to hepatitis B vaccination. Vaccine. 2013;31:J21-8.

17. Techasathit W, Ratanasuwan W, Sonjai A, Sangsiriwut K, Anekthananon T, Suwanagool S. Vaccination against hepatitis B virus: are Thai medical students sufficiently protected. J Med Assoc Thail. 2005;88(3):329-34.

18. Maswanya E, Moji K, Horiguchi I, Nagata K, Aoyagi K, Honda S, Takemoto T. Knowledge, risk perception of AIDS and reported sexual behaviour among students in secondary schools and colleges in Tanzania. Health Educ Res. 1999;14(2):185-96

19. Tahan V, Karaca C, Yildirim B, Bozbas A, Ozaras R, Demir K, Avsar E, Mert A, Besisik F, Kaymakoglu S. Sexual transmission of HCV between spouses. Am J Gastroenterol. 2005;100(4):821.

20. Inaba N, Ohkawa R, Matsuura A, Kudoh J, Takamizawa H. Sexual transmission of hepatitis B surface antigen. Infection of husbands by HBsAg carrier-state wives. Sex Transm Infect. 1979;55(5):366-8.

21. Brener ND, Billy JO, Grady WR. Assessment of factors affecting the validity of self-reported health-risk behavior among adolescents: evidence from the scientific literature. J Adolesc Health. 2003;33(6):436-57.

\section{Publisher's Note}

Springer Nature remains neutral with regard to jurisdictional claims in published maps and institutional affiliations. 